\title{
Incorporating socioscientific issues into a STEM education course: exploring teacher use of argumentation in SSI and plans for classroom implementation
}

\author{
Joseph Johnson ${ }^{1 *}$ D, Augusto Z. Macalalag $\mathrm{Jr}^{2}$ and Julie Dunphy ${ }^{2}$
}

\begin{abstract}
The Socioscientific Issue (SSI) framework was applied to explore how a team of two teachers navigated SSI cases as students in a STEM education graduate program. Using a case study approach, we found a connection between the specific SSI case and levels of scientific argumentation, as well as teachers' plans for teaching. Our findings suggest successes and challenges for our teachers in incorporating scientific argumentation through SSI cases into his/her intended classroom practices. Specifically, our participating teachers displayed notably higher levels of claims, reasoning, and ability to question the sources of information, but lower levels of evidence and rebuttals. They had difficulty in connecting claims to evidence and reasoning in discussing the SSI cases. Moreover, their intended classroom implementation considered how to connect the lessons to their students' lives, build scientific knowledge, and provide meaningful context to engage their students in the study of SSI.
\end{abstract}

Keywords: SocioScientific issues, Teacher preparation, Argumentation

\section{Introduction}

Socioscientific issues (SSI) are authentic, real world, science based controversial issues that, when studied, require students to develop scientific content knowledge as well as moral and ethical reasoning (Zeidler \& Nicols, 2009). SSIs can include a wide variety of topics such as genetic modification, green energy, global warming, animal testing, etc. SSIs include the use of "personally relevant, controversial, and illstructured problems that require scientific, evidence-based reasoning to inform decisions about such topics" (Zeidler, 2014, p. 699). This suggests that the best cases for SSI include those that are local in nature and related to the lives of those grappling with them, whether they be pre-service and in-service teachers or students.

\footnotetext{
* Correspondence: jjohnson@mercyhurst.edu

'Department of Physics, Mercyhurst University, 501 East 38th Street, Erie, PA 16546, USA

Full list of author information is available at the end of the article
}

The science, technology, engineering, and mathematics (STEM) disciplines and programs in schools are currently and typically taught in silos with less or no emphasis on social and cultural experiences of students (Zeidler, 2016). Although there are significant strides to foster cross-cutting concept connections as well as science and engineering practices in classrooms (NGSS Lead States, 2013), lessons tend not to consider students' own personal positions, ability to gather and evaluate evidence, moral and belief system, and understanding of social context that influence how knowledge is constructed and shared (Zeidler, 2016). On the other hand, the STEM disciplines that use a socioscientific lens provide a rich venue for engaging students in relevant, realworld, and oftentimes debatable topics in their community or society in general. When school curriculum presents students with challenging, socially relevant new knowledge, it provides the opportunity to engage in meaningful dialogue and become active participants in the community (Rodriguez \& Berryman, 2002). Moreover, as students engage in 
meaningful discourse and problem solving of an SSI unit, the interpretive scheme of those students is informed by their cultural lives and influenced by dominant narratives they are exposed to from their society (Rose \& Barton, 2012).

Instruction applying SSI has been identified as an avenue for developing students as global citizens (Lee et al., 2013). As such, SSI provides a strong framework for engaging students in meaningful and relevant scientific discourse in the development of functional scientific literacy, which is important for them to effectively participate in society. "Scientific literacy entails the ability to make informed decisions, analyze, synthesize, and evaluate varied sources of data and information, use moral reasoning to attend sensibly to ethical issues, and understand the complexity of connections inherent in SSI" (Zeidler, 2014, p. 697). Inherent to scientific literacy and practices in STEM disciplines is for students to evaluate information and use data in order to engage in argumentation (NGSS Lead States, 2013). In science, aspects of argumentation include the ways students develop and test predictions, construct scientific knowledge, make meaning from observation, make arguments, and participate in scientific processes (Yerrick \& Johnson, 2011). In the Treasures in the Sea: Use and Abuse SSI unit of study, in which high school students in Israel engaged in as part of a national effort to increase scientific literacy, Tal and Kedmi (2006) found that students' arguments improved by providing more justifications to claims and assertions. Moreover, students incorporated more accurate and specific scientific knowledge in their justifications by supporting their claims and counter arguments.

In terms of educating teachers to implement SSI in their classrooms, several researchers have identified a variety of barriers to the successful implementation of SSI instruction. Lee, Abd-El-Khalick, and Choi (2006) found that Korean science teachers perceived a lack of materials as well as a lack of sufficient content knowledge as challenges to implementing SSI cases. Forbes and Davis (2007) also found that preservice teachers cited a perceived insufficient knowledge about the concepts included in their case as a challenge. Sadler and Zeidler (2004) compared two groups of participants based on their level of understanding of science content related to a specific SSI case on gene therapy and cloning. They found that participants in the group with less conceptual understanding were not readily able to demonstrate a high level of reasoning. However, those participants were still able to engage in informal reasoning and express ethical concerns regarding the SSI (Sadler \& Zeidler, 2004). These findings "support the notion that understanding content knowledge is related to the quality of informal reasoning regarding socioscientific issues based on that content knowledge" (Sadler \& Zeidler, 2004, p. 88).

Pre-service and in-service teachers' abilities vary when it comes to engaging in SSI and argumentation. Although a number of science teacher preparation and education programs in the U.S. and abroad have focused on interdisciplinary and crosscutting connections among STEM disciplines and have incorporated practices in science and engineering, fewer programs have engaged teachers in SSI and argumentation (Zeidler, 2016). In a program where SSI was included, most pre-service and in-service teachers recognize the value of teaching through SSI, but do not have the knowledge and pedagogy to implement it in their classrooms (Anagun \& Muhammet, 2010). Espeja and Lagaron (2015) found pre-service teachers' initial ideas of SSI tend to be simplistic and limited, in most cases only referring to ideas or issues that did not include the complex nature of SSI, such as discourse around uncertainty and competing arguments. Moreover, the study conducted by Çalik, Turan, and Coll (2014) showed that it was challenging for prospective teachers to evaluate evidence and to support their arguments. Specifically, they tend to trust arguments from authority figures rather than demand evidence. However, it has also been shown that undergraduate education methods courses and professional development can support teachers in learning how to incorporate SSI instruction (Parr, 2013). For instance, teachers' abilities have shown improvement with course work involving the use of field studies to build teacher knowledge and experience regarding SSI topics (Macalalag, Johnson, \& Lai, 2017). Our research seeks to take a closer look at understanding how teachers engage in argumentation as they navigate selected SSI cases, specifically to answer the following research questions:

- How does a teacher's ability to make a scientific argument vary in addressing two different SSI cases?

- How does the teachers' experiences in their course help them to think about their intended implementation of SSI in their classrooms?

\section{Literature review}

This research study is grounded in the SSI framework described by Zeidler, Sadler, Simmons, and Howes (2005) that includes the engagement of students in culturally relevant scientific issues to develop scientific literacy and understanding along with morality and ethics. The development of this cognitive and ethical scientific literacy consists of four components; nature of science issues, classroom discourse issues, cultural issues, and case-based issues (Zeidler et al., 2005). Students' understanding and application of the nature of science influences how they make evidence-based decisions to address preconceived notions regarding SSI. This is done through the construction of arguments and socially constructed knowledge through discourse about specific, culturally relevant SSI cases (Zeidler et al., 2005). When these components converge, students develop a functional scientific literacy, which ultimately includes the ability to make informed scientific decisions and influence the world around them. 
In a study conducted with elementary students, SSI lessons assisted the development of critical thinking skills in fourth grade students as they engaged in discourse on local and global environmental issues (Burek, 2012). In another study, conducted at the high school level, SSI instruction was also found to support the development of better understanding of scientific theories and the nature of science in high school students (Pinzino, 2012). It also provided opportunities for students to improve their ability to evaluate claims and make arguments based on evidence (Pinzino, 2012). In a study conducted with undergraduate students, the SSI approach to teaching enhanced students' abilities to improve their explanations and decisions toward environmental issues (Zobi, 2014).

Topcu, Sadler, and Yilmaz-Tuzun (2010) examined the extent to which case-based issue contexts affect the informal reasoning and argumentation processes of 39 Turkish preservice science teachers. They used SSI cases related to gene therapy for Huntington's disease (Would you support the use of gene therapy to treat Huntington's disease that does not have conventional treatments?), human cloning (Would you be in favor of allowing reproductive cloning for couples that are infertile and unable to have a baby?), and global warming (How should governments respond to the issue of global warming?). Their results indicated that pre-service teachers were not particularly adept at informal reasoning in the context of SSI. Specifically, they struggled to form robust counter-arguments and rebuttals (Topcu et al., 2010). A study of 1600 elementary student teachers in a Turkish University showed that student teachers tended to trust arguments of authority figures rather than demand evidence even after taking undergraduate courses related to SSIs. Their findings suggested the seriousness of educating pre-service teachers on informal reasoning, argumentation and SSI (Çalik et al., 2014).

Although SSI cases develop scientific literacy, teachers face challenges in their implementation. As such, it is crucial to understand these challenges in both pre-service and inservice teachers in order to better support them. Several research studies have shown the successes and challenges of preparing and helping teachers to incorporate the SSI framework into their STEM lessons. Saunders and Rennie (2013) showed that teachers often lacked the confidence and support to address issues related to SSI classroom implementation. Additionally, while most pre-service and in-service teachers see the value of teaching through SSI, they may not have the knowledge or pedagogical tools to implement it in their classrooms (Anagun \& Muhammet, 2010; Parr, 2013). Another study analyzing pre-service teachers' initial ideas of SSI found they were simplistic and limited, typically referring to ideas or issues that did not include the complex nature of SSI, such as discourse around uncertainty and competing arguments (Espeja \& Lagaron, 2015). However, it was also shown that methods courses and professional development can support teachers in learning how to incorporate SSI instruction (Espeja \& Lagaron, 2015; Parr, 2013). To study inservice teachers' engagement in and ideas for facilitation of SSI, we conducted a case-study with two students enrolled in a graduate STEM course.

\section{Methods}

\section{Research setting, context, and participants}

Our study was conducted following a 3-credit, graduate-level course, ED697 STEM and Society, taught by the second author for 45 h over 5 weeks in the summer of 2016. Our study aimed to investigate how one group of teachers navigated selected SSI cases in their STEM and Society course. The STEM and Society course is an interdisciplinary, problembased course designed to introduce teachers to the synergistic and symbiotic relationships between society and the environment. Specifically, objectives in this course included: (a) collecting, synthesizing, and describing human use, benefit, and dependency on water, (b) identifying and analyzing the human activities and practices that can help or harm the environment, (c) calculating and estimating energy and water demands, (d) analyzing population growth, (e) analyzing the synergistic relationship between society and the environment, (f) comparing and contrasting the role of the environment in the evolution of STEM fields and green technologies, and (g) writing and reflecting on units or lessons that promote the study of society and the environment. Teachers in this course studied and discussed the varying perspectives toward several assigned SSI cases including the mystery of missing bees, the drought in California, the development of wind farms in Massachusetts, the population growth, human impact to the environment, renewable energy and sustainability, and environmental contributions to health and civilization. They also had opportunities to adapt, redesign, or develop lessons that emphasized environmental education for K-12 students.

For instance, as part of the readings and discussions on the case of missing bees, teachers examined the evidence and possible reasons for the colony collapse disorder (CCD). They studied and discussed data presented in articles (see Appendix A) that potentially contributed to CCD such as the use of pesticides poisoning the bees, invasive varroa mite (a pest of honey bees), and stress bees experience due to overworking of bees for providing pollination services in multiple locations. They also reviewed and debated using data presented by the Genetic Literacy Project (see Appendix A) that argued CCD as a myth and claimed that the spikes in bee losses in parts of the world could be attributed to variances in nature in a particular region. Specifically, according to the Genetic Literacy Project webpage, "Typical wintertime losses were in the neighborhood of 10 to 15 percent before 1987 , when the US was hit by the varroa mite, a deadly parasite that decimates hives and vectors in over a dozen viruses and diseases into honeybee hives. Since the varroa infestation began, losses have risen in some years to 30 to 35 percent. 
But this does not mean that the honeybee population is in fatal decline and certainly does not support the pesticides-askiller hypothesis".

In addition to the case-based study of missing bees, teachers also studied the drought in California where they examined the roles of humans such as the water consumption and conservation in homes, schools, industries, and farms. In addressing this SSI, teachers studied the beliefs, attitudes, politics, and culture of obtaining, distributing, using, recycling, and conserving water. In terms of the environment and technology, they reviewed the data on the amount of rainfall over time and discussed the technologies such as dams, irrigation systems, rerouting rivers, and desalination that can possibly intervene or contribute to drought. These SSI contexts provided ways for teachers to enhance their science content knowledge, ability to study the empirical and culturally embedded Nature of Science, and aptitude to evaluate the different assumptions and claims made during a discussion on SSI (Akerson, Cullen, \& Hanson, 2009). In studying these SSI cases, teachers utilized McNeill and Krajcik's (2012) framework to evaluate the claims, evidence, reasoning, and rebuttals from the articles. Specifically, teachers discussed if: (a) the claim is accurate and complete, (b) the articles provided appropriate and sufficient evidence to support the claim, (c) there are any potential biases (e.g. questioning the credibility of the authors, political affiliation, and/ or their sources of data), and (d) the article provided an accurate and complete reasoning to link evidence to claim. Finally, these SSI cases allowed us to engage our teachers in four components of the SSI framework, which are nature of science issues, classroom discourse issues, cultural issues, and case-based issues (Zeidler et al., 2005).

In addition to the study of selected SSI cases, teachers conducted hands-on explorations using Engineering is Elementary (EiE) modules (www.eie.org) that have environmental education and sustainability themes: (a) Water, Water Everywhere: Designing Water Filters, (b) A Slick Solution: Cleaning an Oil Spill, (c) The Best of Bugs: Designing Hand Pollinators, (d) Catching the Wind: Designing Sails and Windmills, and (e) Now You're Cooking: Designing Solar Ovens. For instance, after the study and discussion of missing bees, teachers conducted activities from the EiE's The Best of Bugs: Designing Hand Pollinators module. In the first lesson, they read the storybook Mariana Becomes a Butterfly in which one girl solves a pollination problem. In this unit, teachers acted as agricultural engineers as they applied their knowledge of insect life cycles, plants, and pollination as they tested a variety of materials to design a technology or prototype for pollinating plants by hand. As an assignment, our teachers designed units and lessons to describe how they plan to implement and teach their students about SSI and environmental education concepts.

Finally, teachers conducted field studies in Pennsylvania, U.S.A. and Sicily, Italy, which included a visit to a local arboretum and urban farm where they educate students on the importance of clean water and using local produce. Similar to the work of Dickerson, Dawkins, and Annetta (2007) in which they used fieldwork in geology to enhance their teacher content knowledge and pedagogy to teach earth and environmental science, we used field studies to help them enhance their content and pedagogy of teaching SSI. Specifically, our teachers visited a water treatment facility and wastewater treatment plant where they learned about the process of cleaning the wastewater and treating the water from the river before distributing it to the city for human consumption and usage. Our teachers also conducted a tour of solar and hydroelectric power facilities in Sicily and asked questions to engineers regarding the rate of production and consumption of the region regarding electrical energy. Our teachers were able to compare not only trends in using renewable energy sources in Sicily vs. Pennsylvania, but they were also able to contrast societal practices such as using electricity, selecting houses and vehicles, buying food, and doing errands (Macalalag, Johnson, \& Lai, 2019). For instance, in Siracusa, Sicily, teachers noticed that residents walk to their local wet market almost everyday to buy their food for that day, while residents in Pennsylvania tend to drive their cars to buy 1 or 2 weeks worth of groceries from their local supermarkets. This example comparison provided teachers a cultural context when discussing the carbon footprint of people based on their societal practices (Macalalag et al., 2017). Moreover, the field studies provided knowledge and experiences for teachers to design lesson plans for their students that utilize real-world and science-based controversial issues while considering the nuances and interconnectedness among nature of science, culture, politics, and ethical reasoning when engaging on evidence-based argumentation and decision making (Dickerson et al., 2007; Zeidler \& Nicols, 2009). Finally, the classroom activities, discussions, and field explorations helped teachers to assess, at the local, national, and international levels, how geo-ecological environments give rise to distinct STEM fields, careers, economies, and technologies and to articulate these concepts into current K-12 STEM education.

Our case study focused on one group of two participants enrolled in the course. At the time of the study, Ms. Cooper held a B.S. in Biology with high school biology and middle school science and mathematics teaching certifications. She had 3 years of teaching experience. Our second participant, Ms. Coleman, held a B.S. and Ph.D. in Chemistry and had been an adjunct professor of chemistry for 10 years. We selected these two participants for the case because they were consistent partners for the discussion portion of this assignment, while other participants in the larger study changed partnerships. This allowed us to analyze the differences in conversations between the same partners on two different SSI cases. Furthermore, the conversations between Ms. Cooper and Ms. Coleman were more robust than other 
partnerships, which again allowed for exploration of the differences between the two SSI cases.

The study received approval from the Institutional Review Board (IRB) of the university where the study was conducted and both teachers voluntarily provided their consent to participate in the study. As part of the course described above, teachers read materials available online and evaluated and argued based on the claims and evidence from these readings. Teachers were prompted to identify, explain, and evaluate claims and arguments. They were asked to consider how the issues discussed were relevant to their students and share ways to engage their students in the SSI cases. You can find the articles and guiding questions provided for teachers for the selected SSIs analyzed in Appendix A.

\section{Data}

In order to answer our research questions, we analyzed: (a) the transcripts of audio recorded discussions of selected SSIs and materials provided by the course instructor and (b) SSI lesson plans designed by the participant teachers. For the SSI discussions, teachers were asked to read a set of resource materials from a variety of media sources outlining multiple perspectives on two SSI cases: (1) the Mystery of the Missing Bees and (2) the Drought in California. They were prompted to discuss claims, evidence, and reasoning within each SSI prompt and make rebuttals as necessary (see Appendix A). Teachers were also asked to describe ideas for lessons, instructional activities, or projects that they could implement in their class or school that taught students about the specific SSI case with which they were engaged.

We asked the teachers to answer these prompts individually, to discuss their answers with another teacher, and to record their conversations. Transcripts of the recorded conversations of our participant group were qualitatively analyzed. Teachers were asked to design lessons integrating SSI at the culmination of the course. These lessons were analyzed to provide triangulation for our analysis.

\section{Data analysis}

Our analysis followed Creswell and Poth's (2018) description of a case-study. This qualitative approach involves the selection of a case with defined parameters and multiple sources of information. We analyzed two transcripts using a within-case analysis to understand larger themes in our data. We coded our data set using an iterative process, refining codes during our application to capture emerging themes (Merriam, 1998).

The initial codes were developed and examples were identified by the first two authors using McNeill and Krajcik's (2012) rubric for claims, evidence, reasoning, and rebuttals to analyze the teachers' levels of evidence based argumentation on the SSI cases described above.
According to these authors, a claim is defined as "a statement or conclusion that answers the original question or problem" (p. 22). A level two claim is clear and fully explained with a direct connection to the SSI, while a level one claim may be accurate, yet incomplete in its connection to the problem. Evidence is defined as "scientific data that support the claim" (p. 23). Level two evidence is accurate, sufficient, and directly supports the claim, while level one may be insufficient or lack a connection to the claim. The code reasoning includes a justification about why the evidence relates to the claim, including scientific principles. Level two reasoning uses sufficient scientific principles to connect the claim and evidence, while level one reasoning may include insufficient scientific principles or fail to draw a connection between the claim and evidence. A rebuttal recognizes an alternate claim and gives supporting evidence and reasoning. A level two rebuttal is accurate and includes sufficient reasoning, while a level one rebuttal may also be accurate, yet lacks evidence or reasoning.

These codes were first applied to individual comments in teachers' conversations. Individual comment codes were then used to assign each conversation a holistic score for the four codes. Examples at various levels of the rubric were identified by all authors. As additional themes emerged, the codes questioning the source of the evidence and identifying questions for further inquiry were created.

The transcripts were also coded using the Framework for the Programme for International Student Assessment (PISA), which included: (a) personal, social, and global contexts, (b) scientific knowledge, (c) attitudes toward science, and (d) scientific competencies (Bybee, 2010). The first and third authors, double-coded one of the two transcripts with $88 \%$ agreement. Any disagreements that occurred were discussed and negotiated, and agreed upon codes were included in this study. The remaining transcript was analyzed by the third author.

The secondary codes we applied from Bybee's (2010) Framework for PISA categories related to teachers' intentions in using SSI in their practice. The code personal, social, and global contexts was used when teachers discussed "life situations that involve science and technology" (p. 99). The code scientific knowledge was applied when teachers discussed classroom activities which would build students' "knowledge of science and knowledge about science" (p. 99) including scientific inquiry and explanations. We applied the code attitudes toward science when teachers discussed activities to promote "interest in science, support for scientific inquiry, and motivation to act responsibly toward" (p. 99). Finally, we used the code scientific competencies when teachers intended to engage students in "identifying scientific questions, explaining phenomena scientifically, 
and using scientific evidence as the basis for arguments, conclusions, and decisions" (p. 99). Analysis focused on patterns between claims, evidence, reasoning, and rebuttals and the PISA codes related to intentions for implementation.

Lesson plans were analyzed with a rubric adapted from Jacobs, Martin, and Otieno (2008), included in Appendix B. We used the rubric to look for evidence of teacher abilities including accuracy of the big idea, context used for SSI cases, and classroom discourse. A level two rating for accuracy of big ideas would be accurate, explicitly described, and well aligned with activities, whereas a level one rating big idea would be accurate, but not well explained, or may not be aligned with activities planned. A level zero would either not include a big idea or include an inaccurate big idea. A level two rating for meaningful context to promote SSI would include students' prior knowledge and background, including culture, promote the discussion of relevant SSI, and encourage problem solving and inquiry. A level one would include at least one of those three areas, while a level zero may not include any. The final area of lesson focus for this study is classroom discourse. A level two lesson would engage students in making or identifying a claim and evaluate and explain evidence, with lesson structure requiring student discussion for the purpose of sense making. Additionally, it includes suggested questions to facilitate discourse. A level one may include discussion opportunities for sense making, but not include enough structure to require all to participate and support them in doing so. The lesson plans analyzed in this study were part of the larger data set of the overall project. Initially, half of the lesson plans in the data set were double-coded by the authors with $90 \%$ agreement. Any disagreements in coding that occurred were discussed and negotiated until 100\% agreement was reached and the remaining lesson plans were coded.

\section{Results}

\section{Evidence-based arguments}

In addressing our first research question regarding how a teacher's ability to make scientific argument varies in different cases, we explored teacher responses to both cases. Table 1 presents a summary of the codes and quotes from teachers' transcripts with quantitative codes. In our analysis of the two teachers' responses to the SSI case of missing bees, participants had claims at level two, including a number of valid claims from the resources. They cited overworking the bees for pollination, viruses, parasites, and cell phone towers as claims about the decrease in bee population. In the SSI of the drought in California, participants made claims at level one, sometimes citing claims in a vague, incomplete manner, such as, "there's an increase in population" (Ms. Cooper) as reasons for the drought. This claim lacks context and supporting evidence.

In terms of evidence the participants presented level one evidence in both the bees and the drought cases. An example of level one evidence is, "...yet the fourth article is the one that actually has the numbers. And when you look at the numbers, it's not that big of a decline" (Ms. Coleman). This example provides vague evidence and is not explicitly tied to a specific claim.

Reasoning for the bees case was coded at level two while the drought reasoning was coded at level one. An example of level two reasoning is, "Okay, the pesticides I guess that's one of the ones that could be tested. You crush up the bees or their honey or whatever and see if the pesticide or metabolic of the pesticide is there" (Ms. Coleman). This is directly linked to a claim and the teacher used background information about the ability to identify viruses and pesticide residue to further explore which of the claims is most valid. The drought transcript included very little reasoning. One example is, "So I'm thinking that it's groundwater" (Ms. Cooper). Here the reasoning included was insufficient to support the claim about precipitation and stream flow.

The rebuttals for the bee case and the drought case were both coded at level one. An example of level one rebuttal is "there was the cell phone towers disoriented the bees. Of course there was no link, at least in the four articles we had, there's no link there" (Ms. Coleman). This rebuttal cites a lack of evidence as the only support for the cell phones claim as invalid.

Both transcripts showed evidence of the participants questioning the sources. An example is "...some of these had false information. Yeah, was our agricultural getting 80 percent of the water or 40 percent of the water?" (Ms. Cooper). The bees case included examples of questions for further inquiry while the drought case did not. An example is, "...what are some other animals or plants going through the same type of deaths or problems, and you know, what are scientists doing to help that?" (Ms. Cooper).

Overall, the participants had higher levels of claims and reasoning when engaged in the case of the bees, than the case of the droughts. They included level 1 examples of evidence, minimal rebuttal, and both questioned the sources of information in both cases, but only included questions for further inquiry in the bees case.

\section{Classroom implementation}

Our second research question, investigating how teachers' experiences in their course help them to think about their intended implementation of SSI in their classrooms, was explored via analysis of the bees and the 
Table 1 Examples of highest coded claim, evidence, reasoning, and rebuttal from each case

Claim
A statement or conclusion that answers the
original question/problem.
Evidence
Scientific data that support the claim. The data
need to be appropriate and sufficient to
support the claim.

\section{Reasoning}

A justification that connects the evidence to the claim. It shows why the data count as evidence by using appropriate and sufficient scientific principles.

\section{Rebuttal}

Recognizes and describes alternative explanations, and provides counter evidence and reasoning for why the alternative explanation is not appropriate.

Missing bees
"They thought that maybe it was a virus, and
once one bee got it was a rapidly contagious
virus and they were constantly getting killed off"
(Ms. Cooper).
Level 2
"They're taking these beehives, and they're going
to different states to go to different farmlands to
make the bees pollinate all these different crops"
(Ms. Cooper). Level 1
I guess that's one of the ones that could be
tested. You crush up the bees or their honey or
whatever and see if the pesticide or metabolic of
the pesticide is there. That one I think you can
actually test. The virus that the bees are getting
and the parasitic mite I would think for people
who were experts, they could dissect the bee
and find out (Ms. Coleman). Level 2

"There was the cell phone towers disoriented the bees. Of course there was no link, at least in the four articles we had, there's no link there" (Ms. Coleman). Level 1

\section{Drought}

"The farmers take to (sic) much..." (Ms. Cooper). Level 1

"Yeah, was our agricultural getting $80 \%$ of the water or $40 \%$ of the water?" (Ms. Cooper). Level 1

"So I'm thinking that it's ground water. So even if there's... less than normal rainfall, the fact that the aquifers haven't refilled so that's why there's still drought" (Ms. Cooper). Level 1

"The other person goes 'Hey, it's all because of Colorado rivers' and the other is like 'Nooo, the urbans aren't cutting back, the farmers need to cut back'" (Ms. Coleman). Level 1 drought cases. Table 2 includes quotes coded for intended implementation. Both cases included examples coded as personal, social, and global contexts. This code was used when teachers were able to find ways to connect the SSI case to their students' lives in a meaningful way. Through their own first hand experience exploring this SSI, they explicitly identified the relevance of the issue to their students. In examples demonstrating personal, social, and global contexts, teachers often cited their students' local environment, experiences, and foods that they eat.

The next code we found evidence for was scientific knowledge. This code was applied to ideas for implementation, which would build students' knowledge of and about science. One example of this in the missing bees case is when teachers are discussing pollination by insects and ways in which they might help students build scientific explanations. The teachers discuss ways to help their students organize their ideas about the content and show how it is related visually. The drought transcript did not include any language coded as scientific knowledge.

Further exploration of participant created SSI lesson plans revealed Ms. Coleman's plan was coded at level 2 for "Accuracy of Big Idea," indicating strong understanding of the content within this particular case. Ms. Coleman's lesson plan contained accurate information about dietary fats, such as olive oil containing phenolic compounds, and the instructional activities, such as testing melting points aligned with this big idea. Her plan was also coded as level 2 for "Meaningful Context to Promote SSI" and included prior knowledge and common misconceptions about the SSI case on olive oil production. Ms. Coleman also included opportunities for discussion around various sources, including medical journals and news clips, and inquiry investigations in which students taste test and measure melting points of different olive oils. Furthermore Ms. Coleman's lesson was coded as level 2 for "Promoting Classroom Discourse." Her plan included both opportunities for sense-

Table 2 Examples of intended implementation

\begin{tabular}{|c|c|c|}
\hline & Missing bees & Droughts \\
\hline $\begin{array}{l}\text { Personal, social, } \\
\text { and global } \\
\text { contexts }\end{array}$ & $\begin{array}{l}\text { And not only that, but being in Delaware almost half my kids } \\
\text { are farmers...if you eventually get a farm, you're going to need } \\
\text { to know how to pollinate" (Ms. Cooper). }\end{array}$ & $\begin{array}{l}\text { "Well, you know, I don't think Delaware would have a problem } \\
\text { with drought, but they could probably imagine that they're a } \\
\text { farmer," followed by, "And if you have less rain, you have less } \\
\text { produce yield. Therefore, what's your profit gonna be?" (Ms. } \\
\text { Cooper). }\end{array}$ \\
\hline $\begin{array}{l}\text { Scientific } \\
\text { knowledge }\end{array}$ & $\begin{array}{l}\text { "On the whiteboard or Smartboard, create a web and put like } \\
\text { honeybees and then do some causes and effects like what do } \\
\text { they help, what is it hurting, and how does that affect and } \\
\text { branch out? (Ms. Cooper). }\end{array}$ & -No evidence \\
\hline
\end{tabular}


making through classroom discourse, as well as structured discussion times in small groups and planned questions. Ms. Cooper's lesson however was coded at level 1,1 , and 0 respectively. It is evident that stronger understanding of the SSI and the STEM content, as coded in this study as "Accuracy of the Big Idea", were associated with an increased effectiveness in fostering discourse and promoting engagement in the SSI amongst students, as coded in this study as "Meaningful Context to Promote SSI" and "Promoting Classroom Discourse".

\section{Discussion}

Our findings suggest successes and challenges of our teachers in incorporating scientific argument through SSI cases to his/her intended classroom practices. Unlike the studies of Anagun and Muhammet (2010) and Parr (2013) that saw most pre-service and in-service teachers did not have the knowledge and pedagogy to implement SSI in their classrooms, the two teachers in our study were able to think of how to connect the lessons to their students' lives, develop scientific knowledge, and provide meaningful context to engage their students in the study of SSI. Unlike previous studies (Çalik et al., 2014; Kim, Anthony, \& Blades, 2014; Topcu et al., 2010) that showed teachers were not familiar with critically challenging information and evidence they and their peers used during argumentation, our analysis showed that our teachers had higher levels of claims and reasoning when engaged in the case of the bees compared to the case of the drought. Both participants included level 1 types of evidence, minimal rebuttal, and both questioned the sources of information during the process of argumentation through both SSI cases. The differences in levels of claims and reasoning between cases may have been due, in part, to the participants' level of familiarity and interest in the selected SSIs As Sadler and Zeidler (2004) described, less conceptual understanding implies a reduced ability to demonstrate a high level of reasoning. Rodriguez and Berryman (2002) pointed out that challenging and socially relevant new knowledge provides the opportunity to engage in meaningful dialogue. Perhaps the selected SSI cases differed in social relevance for our participants, leading to differing levels of engagement and quality of claims and reasoning. The nature of SSI guides learners to evaluate multiple perspectives within individual SSI cases. Personal experience with and interest in specific SSI cases may provide important context for exploring issues from different points of view, while insufficient knowledge and understanding can pose a serious challenge, limiting the quality of reasoning (Forbes \& Davis, 2007; Sadler \& Zeidler, 2004).

\section{Implications}

Our data showed that our participating teachers had difficulty in connecting claims to evidence and reasoning in discussing the SSI cases. This has major implications in that teachers implementing SSI to foster functional scientific literacy necessarily must model the desired discourse practices. As Lemke (1998) asserted, in facilitating scientific argument focusing on evidence and the construction of explanations by students, the teacher's role must shift to someone who can model for students how scientists talk, write, diagram, calculate, plan, observe, and record. They must be able to demonstrate how to represent and analyze data, how to formulate hypotheses and conclusions, and how we connect theories, models (Lemke, 1998). As such, STEM education programs must make explicit and concerted efforts towards developing teachers' scientific discourse abilities if those teachers are expected to model these practices as they implement SSIs in their classrooms. If this unpacking of science discourse is not actively pursued and promoted, it never develops on its own (Michaels \& O'Connor, 1990) and teachers tend to revert back to more traditional methods of communicating in their STEM classrooms. Teacher educators must provide a variety of experiences in which developing teachers directly participate in SSI from the students' point of view. In doing so, teachers will develop a repertoire of SSI contexts and strategies, while also learning how to learn, develop, and implement their own SSI lessons focusing on contexts specific to their classroom.

It is also evident from our data that stronger understandings of selected SSIs and the STEM content involved with those SSIs were associated with an increased effectiveness in fostering discourse and promoting engagement for the participants both as learners and in preparing lessons. For our participants, field studies and firsthand classroom participation with a variety of SSIs provided them with experiences from which they were able to develop perspectives and attach concrete actions and contexts to specific SSIs. As such, firsthand use of a variety of SSI cases relevant to students' background is a necessary component to teacher development in any teacher education programs aiming to foster STEM educators' implementation of SSIs. Experience with the use of multiple SSI cases within a teacher preparation program will better prepare teachers to give students opportunities to build understanding and background of unfamiliar cases. Culturally relevant cases with familiar content may allow for deeper engagement in argumentation and application to teachers' future instruction, allowing them to better align selected cases to student interests and backgrounds.

While the case study design allowed us substantial depth in understanding, we also recognize the limitations of the scope of our study. Our case study only included two participants with two selected SSI. In addition, we collected data about teachers' intended 
SSI classroom implementation. Future research is needed, expanding to a wider variety of SSI cases and participants. Additionally, including classroom observations following program completion may contribute to further generalizability of findings.

\section{Conclusions}

In light of the focus in SSI implementation on the development of functional scientific literacy among students (Zeidler et al., 2005), teachers must be able to plan for the development of scientific competencies while using SSI cases in their classrooms. Our analysis showed successes and challenges of our teachers, with notable higher levels of claims and reasoning and ability to question the sources of information, but lower levels of evidence and rebuttals. Their intended classroom implementation considered how to connect the lessons to their students' lives, build scientific knowledge, and provide meaningful contexts to engage their students in the study of SSI. We suggest that future research and coursework for in-service and pre-service teachers should consider and build upon the successes and challenges that we learned from our teachers.

\section{Appendix A}

Reflections and Discussions about the Socio-Scientific Issues (SSI)

Instructions: Individual Reflection and Partner Discussions

1. Read the guiding questions and write their answers on a piece of paper

2. Read the articles and view the videos provided, which present a case in SSI.

3. Discuss your individual reflections with a partner and record their discussions using Voice Memos from iPhone.

4. Collect the individual reflection papers and submit the recorded voice memos to (first author).

Guiding Questions:

1. What is (are) the issue(s)?

2. Identify and explain the claims or arguments presented in the articles and videos.

3. What can you say about these claims and arguments? (or evaluate the claims and arguments made in the articles)

4. What questions do you have or additional information you need in order to have a better understanding of the issue(s)?

5. To what extent do you think this/these issue(s) is/ are relevant to your students?

6. In what ways can you engage your students to think about this/these issue(s)?
The Mystery of Missing Bees

1. Haberman, C. (2014, September 28). The HeadScratching Case of the Vanishing Bees. Retrieved in July 2016, from http://www.nytimes.com/2014/09/2 9/us/the-head-scratching-case-of-the-vanishingbees.html?_r=0

2. U.S. Environmental Protection Agency. (n.d.). Colony Collapse Disorder. Retrieved in July 2016, from https://www.epa.gov/pollinator-protection/ colony-collapse-disorder

3. Entine, J., Genetic Literacy Project Staff, and Contributing Writers. (2016, July 28). Beepocalypse Myth Handbook: Dissecting claims of pollinator collapse. Retrieved in July 2016, from https://www. geneticliteracyproject.org/2015/07/30/beepocalypsemyth-handbook-dissecting-claims-of-pollinatorcollapse/

The California's Drought

1. U.S. Geological Survey. (n.d.). Droughts: Things to know. Retrieved in July 2016, from https://water. usgs.gov/edu/qadroughts.html

2. U.S. Environmental Protection Agency. (n.d). WaterSense. Retrieved in July 2016, from https:// www.epa.gov/watersense

3. Zamora, A., Lustgarten, A., and Kirchner, L. (2015, June 25). California's Drought is Part of a Much Bigger Water Crisis. Here's What You Need to Know. Retrieved from https://www.propublica.org/ article/california-drought-colorado-river-watercrisis-explained

4. Starr, P. (2015, April 13). EPA and CA Drought: "What Civilized Society Destroys Its Own Food Source For A Three-Inch Fish?" Retrieved in July 2016, from http://cnsnews.com/blog/penny-starr/ epa-and-ca-drought-what-civilized-society-destroysits-own-food-source-three-inch

5. Northern California Water Association (2015, April 23). Top Four Myths of the California Drought. Retrieved in July 2016, from http://www. norcalwater.org/2015/04/23/top-four-myths-of-thecalifornia-drought/

\section{Appendix B}

Lesson Analysis Rubric

Adapted from Jacobs, C. L, Martin, S.N. \& Otieno, T.C. (2008). A Science Lesson Plan Analysis Instrument for Formative and Summative Program Evaluation of a Teacher Education Program. Science Education, pp. 1096-1126 


\begin{tabular}{|c|c|c|}
\hline Criteria & Exemplary & Making progress \\
\hline $\begin{array}{l}\text { 1. Alignment with } \\
\text { standards (Weight 1) }\end{array}$ & $\begin{array}{l}\text { Direct and explicit links to appropriate } \\
\text { NGSS, state, and/or district process AND } \\
\text { content standards }\end{array}$ & $\begin{array}{l}\text { Clearly contributes to students learning } \\
\text { of one or more standards or } \\
\text { benchmarks, which are not explicitly } \\
\text { listed } \\
\text { OR } \\
\text { Either process or content standards are } \\
\text { ignored or vague }\end{array}$ \\
\hline $\begin{array}{l}\text { 2. Goal orientation } \\
\text { (Weight 2) }\end{array}$ & $\begin{array}{l}\text { Explicit learning goals and objectives for } \\
\text { the unit are comprehensive and clearly } \\
\text { comprise a big idea of science. Lesson } \\
\text { activities clearly support goals and } \\
\text { objectives. }\end{array}$ & $\begin{array}{l}\text { Learning goals and objectives are } \\
\text { accurate, but } \\
\text { o Are implied rather than explicitly } \\
\text { stated } \\
\text { o Do not fully encompass the big idea } \\
\text { of the topic are } \\
\text { - Are too vague to asses or include } \\
\text { inappropriate level of detail } \\
\text { - Are not completely supported by the } \\
\text { lesson activities }\end{array}$ \\
\hline $\begin{array}{l}\text { 3. Accuracy of the Big Idea } \\
\text { (Weight 3) }\end{array}$ & $\begin{array}{l}\text { The big idea of the lesson is accurate, } \\
\text { explicitly described, and aligned with } \\
\text { the instructional activities. }\end{array}$ & $\begin{array}{l}\text { The big idea of the lesson is accurate, } \\
\text { but } \\
\text { o Not explicitly described } \\
\text { OR } \\
\text { O The instructional activities are not } \\
\text { aligned }\end{array}$ \\
\hline assessmen & IEssol & sson plan does include pre- \\
\hline
\end{tabular}

The lesson plan is structured to actively solicit students' preconceptions at the start of a topic, and refers to possible ways in which instruction could be modified in response to pre-assessment information.

5. Identification of students' prior knowledge (Weight 2)

6. Meaningful context to promote socio-scientific issue (Weight 3)

7. Classroom discourse Fostering a community of learners (Weight 3)

8. Appropriate use of electronic technology (Weight 1 if applicable to the lesson)

9. Student practitioners of science inquiry, engineering
The lesson plan includes accurate and expected students' prior knowledge and possible alternative conceptions. It considers the students' prior knowledge and alternative conceptions in the design of instructional activities.

The context provided (at least two of the following)

- Considers the students' prior knowledge and background (interests, culture, etc.

- Promotes discussion of relevant socioscientific issue

- Encourages problem solving or inquiry

Students are part of a learning community:

- Lesson is structured for students to make or identify a claim and evaluate and explain evidence

- Lesson is structured to require significant discussion among students focused on sense making - Suggested guide questions to facilitate discourse of socio-scientific issue and/or problem are provided

Appropriate use of available electronic technology (e.g., digital projector, Smart Board, laboratory probes, Internet resources)

Lesson allows students to engage in the Lesson allows students to engage in science and engineering practices such the science and engineering practices

The lesson plan includes accurate and expected students' prior knowledge, but conceptions

$\mathrm{OR}$

- Does consider the students' prior in the design of instructional activities.

The context provided (at least one of the following)

- Considers the students' prior

knowledge and background (interests, culture, etc.)

- Promotes discussion of relevant socio-scientific issue

- Encourages problem solving or inquiry

Lesson is structured to allow for (but not require) meaningful student discussion that furthers conceptual understanding

$\mathrm{OR}$ assist students to conduct a discourse resources
Needs improvement

Incorrect or missing standards assessment activities, but information is not used to inform instruction OR teacher simply attempts to refute or replace alternative conceptions with correct information.

- Does not include possible alternative knowledge and alternative conceptions

Not enough structure or scaffolding to

Learning goals and objectives - Are not implied by the planned learning objectives

- Reflect an inaccurate understanding of the topic - Do not help students attain understanding of the big idea o Are not reflected in the planned learning objectives

The big idea is not accurate OR

Not included in the lesson

The lesson does not reflect an understanding that students' preconceptions can affect how they understand new information.

The lesson plan does not include expected students' prior knowledge

$\mathrm{OR}$

Identified an inaccurate prior knowledge

The context provided does not consider students' prior knowledge and background (interests, culture, etc.) OR

Does not promote discussion of socio-scientific issue

$\mathrm{OR}$

Will not encourage problem solving or inquiry.

- Lesson structure inhibits meaningful discussion

- Lesson does not allow for classroom discourse

- Teacher or text acts as authority figure who provides the "correct answer" and curtails discussion

Could better utilize available technology Inappropriate use of technology that distracts students from learning

Lesson allows students to engage in the science and engineering 
(Continued)

\begin{tabular}{llll}
\hline Criteria & Exemplary & Making progress & Needs improvement \\
\hline design, and/or problem- & as (ALL) & such as (at least two of the following) & practices such as (at least one of \\
based learning (Weight 6) & ○ Asking question and/or defining & $\circ$ Asking question and/or defining & the following) \\
& problem & problem & $\circ$ Asking question and/or \\
& o Developing, testing, and revising & $\circ$ Developing, testing, and revising & defining problem \\
& scientific or engineering model & scientific or engineering model & $\circ$ Developing, testing, and \\
& ○ Conducting claim- evidence- & $\circ$ Conducting claim- evidence- & revising scientific or engineering \\
& explanation-argumentation & explanation-argumentation & model \\
& & & $\circ$ Conducting claim- evidence- \\
& & & explanation-argumentation
\end{tabular}

10. Student reflection (Weight 2)

\section{Assessment}

Either individually or as class, students are required to reflect on and summarize their understanding verbally or in writing at an appropriate point(s) during the lesson(s) in order to build conceptual understanding
- Includes effective tool(s) that assess for conceptual understanding - Includes criteria and/or rubrics for performance-based assessments (reports, participation, etc.) if necessary
- Assessment results used to modify the lesson as it is being taught, and as formative feedback to students
Includes tools or suggestions for assessment that may address conceptual understanding but emphasize factual recall

Lesson is structured to allow for (but not fully promote or support) meaningful student reflection or summation that furthers conceptual understanding
Time is not reserved for student summation or other reflective practices
Assessment tools do not measure student conceptual understanding $\mathrm{OR}$ there is no assessment tool or method described

\section{Acknowledgements \\ Not applicable.}

\section{Authors' contributions}

Dr. Macalalag taught the graduate course and collected all data from participants. Dr. Macalalag and Dr. Johnson identified and modified rubrics used for analysis. All three authors were involved in the analysis and interpretation of the data and were major contributors to the writing of this manuscript. All authors read and approved the final manuscript.

\section{Authors' information}

Dr. Joseph Johnson is an Associate Professor of Physics at Mercyhurst University. He teaches physics and science education courses to undergraduate and graduate Science, Technology, Engineering, and Mathematics (STEM) students and preservice teachers. Dr. Augusto Z. Macalalag, Jr. is an Associate Professor of STEM Education. He led the development of the STEM Education Graduate Certificate program at Arcadia University that includes five graduate courses with environmental education field studies in Philadelphia, PA and Sicily, Italy. Dr. Macalalag teaches courses in the STEM program for practicing teachers and undergraduate and graduate science methods courses to prospective teachers. Julie Dunphy is a K-12 Instructional Coach, currently pursuing a doctoral degree in educational leadership at Arcadia University.

\section{Funding}

Not applicable.

\section{Availability of data and materials}

The datasets used and/or analyzed during the current study are available from the corresponding author on reasonable request.

\section{Competing interests}

The authors declare that they have no competing interests.

\section{Author details}

'Department of Physics, Mercyhurst University, 501 East 38th Street, Erie, PA 16546, USA. ${ }^{2}$ School of Education, Arcadia University, 450 S. Easton Road, Glenside, PA 19038, USA.
Received: 3 February 2020 Accepted: 13 July 2020

Published online: 05 August 2020

\section{References}

Akerson, L., Cullen, T., \& Hanson, D. L. (2009). Fostering a community of practice through a professional development program to improve elementary teachers' views of nature of science and teaching practice. Journal of Research in Science Teaching, 46(10), 11090-11113.

Anagun, S. S., \& Muhammet, D. (2010). Teacher candidates' perceptions regarding socio-scientific issues in science and technology instruction. Social and Behavioral Science, 9, 981-985

Burek, K. (2012). The impact of socioscientific issues based curriculum involving environmental outdoor education for fourth grade students.

Bybee, R. (2010). The teaching of science: 21st century perspectives. Arlington: NSTA Press.

Çalik, M., Turan, B., \& Coll, R. K. (2014). A cross-age study of elementary student teachers' scientific habits of mind concerning socioscientific issues. International Journal of Science and Mathematics Education, 12(6), 1315-1340. https://doi.org/10.1007/s10763-013-9458-0.

Creswell, J. W., \& Poth, C. N. (2018). Qualitative inquiry \& research design: choosing among the five approaches, (4th ed., ). Thousand Oaks: Sage Publications.

Dickerson, D. L., Dawkins, K. R., \& Annetta, L. (2007). Scientific fieldwork: an opportunity for pedagogical-content knowledge development. Journal of Geoscience Education, 55(5), 371-376.

Espeja, A. G., \& Lagaron, D. G. (2015). Socio-scientific issues (SSI) in initial training of primary school teachers: pre-service teachers' conceptualization of SSI and appreciation of the value of teaching SSI. Social and Behavioral Science, 196, $80-88$.

Forbes, C. T., \& Davis, E. A. (2007). Exploring preservice elementary teachers' critique and adaptation of science curriculum materials in respect to socioscientific issues. Science \& Education, 17(8), 823-854.

Jacobs, C. L., Martin, S. N., \& Otieno, T. C. (2008). A science lesson plan analysis instrument for formative and summative program evaluation of a teacher education program. Science Education, 92, 1092-1126. https://doi.org/10. 1002/sce.20277.

Kim, M., Anthony, R., \& Blades, D. (2014). Decision making through dialogue: a case study of analyzing preservice teachers' argumentation on socioscientific issues. Research in Science Education, 44, 903-926.

Lee, H., Abd-El-Khalick, F., \& Choi, K. (2006). Korean science teachers' perceptions of the introduction of socio-scientific issues into the science curriculum. Canadian Journal of Science, Mathematics, and Technology Education, 6(2), 97117 
Lee, H., Yoo, J., Choi, K., Kim, S. W., Krajcik, J., Herman, B. C., \& Zeidler, D. L. (2013). Socioscientific issues as a vehicle for promoting character and values for global citizens. International Journal of Science Education, 35(12), 2079-2113.

Lemke, J. L. (1998). Teaching all the languages of science: words, symbols, images and actions. Retrieved from: http://academic.brooklyn.cuny.edu/education/ jlemke/papers/barcelon.htm.

Macalalag, A., Johnson, J., \& Lai, M. (2017). STEM education course: enhancing K12 teachers' cultural awareness through reflections of Socioscientific issues. Pennsylvania Teacher Educator, 16, 76-92.

Macalalag, A., Johnson, J., \& Lai, M. (2019). How do we do this: learning how to teach socioscientific issues. Cultural Studies of Science Education, 3(8), 1-25. https://doi.org/10.1007/s11422-019-09944-9.

McNeill, K. L., \& Krajcik, J. S. (2012). Supporting grade 5-8 students in constructing explanations in science: the claim, evidence, and reasoning framework for talk and writing. New York: Pearson.

Merriam, S. B. (1998). Qualitative research and case study applications in education. San Francisco, CA: Jossey-Bass Publishers.

Michaels, S., \& O'Connor, M. C. (1990). Literacy as reasoning within multiple discourses: implications for policy and educational reform. Boston: Paper presented at the meeting of The Council of Chief State School Officers 1990 Summer Institute.

NGSS Lead States (2013). Next generation science standards: For States, by States. Washington, DC: The National Academies Press.

Parr, J.C. (2013). View of socioscientific issues among educators: the willingness of teachers to accept SSI into the classroom and the reason underlying those beliefs. (Doctoral dissertation). Retrieved from http://aquila.usm.edu/ dissertation $/ 530$.

Pinzino, D.W. (2012). Socioscientific issues: a path towards advanced scientific literacy and improved conceptual understanding of socially controversial scientific theories. (Graduate theses and dissertations). Retrieved from http:// scholarcommons.usf.edu/etd/4387.

Rodriguez, A. J., \& Berryman, C. (2002). Using sociotransformative constructivism to teach for understanding in diverse classrooms: a beginning teacher's journey. American Educational Research Journal, 39(4), 1017-1045.

Rose, S. L., \& Barton, A. C. (2012). Should Great Lakes City build a new power plant? How youth navigate Socioscientific issues. Journal of Research in Science Teaching, 49(5), 541-567.https://doi.org/10.1002/tea.21017.

Sadler, T. D., \& Zeidler, D. L. (2004). The significance of content knowledge for informal reasoning regarding socioscientific issues: applying genetics knowledge to genetic engineering issues. Science Education, 89(1), 71-93. https://doi.org/10.1002/sce.20023.

Saunders, K. J., \& Rennie, L. J. (2013). A pedagogical model for ethical inquiry into socioscientific issues in science. Research in Science Education, 43(1), 253-274.

Tal, T., \& Kedmi, Y. (2006). Teaching socioscientific issues: classroom culture and students' performances. Cultural Studies of Science Education, 1(4), 615-644. https://doi.org/10.1007/s11422-006-9026-9.

Topcu, M. S., Sadler, T. D., \& Yilmaz-Tuzun, O. (2010). Preservice science teachers' informal reasoning about Socioscientific issues: the influence of issue context. International Journal of Science Education, 32(18), 2475-2495.

Yerrick, R.. \& Johnson, J. (2011). Negotiating white science in rural black America: a case for navigating the landscape of teacher knowledge domains. Cultural Studies of Science Education, 6(4), 915-939.

Zeidler, D. L. (2014). Socioscientific issues as a curriculum emphasis: theory, research, and practice. In N. G. Lederman, \& S. K. Abell (Eds.), Handbook of research on science education, (vol. 2). New York: Routledge.

Zeidler, D. L. (2016). STEM education: a deficit framework for the twenty first century? A sociocultural socioscientific response. Cultural Studies of Science Education, 11, 11-26. https://doi.org/10.1007/s11422-014-9578-z.

Zeidler, D. L., \& Nicols, B. H. (2009). Socioscientific issues: theory and practice. Journal of Elementary Science Education, 21(2), 49-58.

Zeidler, D. L., Sadler, T. D., Simmons, M. L., \& Howes, E. V. (2005). Beyond STS: a research-based framework for socioscientific issues in education. Science Education, 89, 357-377.

Zobi, A. S. (2014). The effect of using socio-scientific issues approach in teaching environmental issues on improving students' ability of making appropriate decisions towards these issues. International Education Studies, 7(8), 113-123. https://doi.org/10.5539/ies.v7n8p113.

\section{Publisher's Note}

Springer Nature remains neutral with regard to jurisdictional claims in published maps and institutional affiliations.

\section{Submit your manuscript to a SpringerOpen ${ }^{\odot}$ journal and benefit from:}

- Convenient online submission

- Rigorous peer review

- Open access: articles freely available online

- High visibility within the field

- Retaining the copyright to your article

Submit your next manuscript at $\boldsymbol{\nabla}$ springeropen.com 